\title{
Improving regional variation using quality of care measures
}

This article was published in the following Dove Press journal:

Risk Management and Healthcare Policy

18 November 2009

Number of times this article has been viewed

\author{
Scott A Berkowitz' \\ Gary Gerstenblith' \\ Robert Herbert ${ }^{2}$ \\ Gerard Anderson ${ }^{1,2}$ \\ 'Department of Medicine, \\ Johns Hopkins University School \\ of Medicine, Baltimore, MD, USA \\ ${ }^{2}$ Center for Hospital Finance \\ and Management, Johns Hopkins \\ Bloomberg School of Public Health, \\ Baltimore, MD, USA
}

\begin{abstract}
There is significant regional variability in the quality of care provided in the United States. This article compares regional performance for three measures that focus on transitions in care, and the care of patients with multiple conditions. Admissions for people with ambulatory care-sensitive conditions, hospital readmissions within 30 days of discharge, and compliance with practice guidelines for people with three chronic conditions (congestive heart failure, chronic obstructive pulmonary disease, and diabetes) were analyzed using data drawn from the Centers for Medicare \& Medicaid Services' Standard Analytic Files for $5 \%$ of a 2004 national sample of Medicare beneficiaries which was divided by hospital referral regions and regional performance. There were significant regional differences in performance which we hypothesize could be improved through better care coordination and system management.
\end{abstract}

Keywords: performance, quality, chronic condition, ambulatory care, sensitive conditions, readmissions

\section{Introduction}

Wennberg and others have documented large regional variations in how medical care is provided $^{1}$ and Schoen and others reported large regional differences in health outcomes across various regions in the United States. ${ }^{2}$ In attempting to improve the quality and consistency of care provided across the United States, health service researchers have developed numerous process and outcome measures to permit comparisons across geographic regions and encourage quality improvement. Many of these indicators focus on the care provided by individual hospitals or physicians but relatively few of them focus on the care that occurs in the transition from inpatient to outpatient care or focus on patients with multiple chronic conditions. These individuals often require the care of multiple providers, and therefore, the ability of the community to coordinate care becomes important. These measures will be useful to evaluate the impact of community-based initiatives such as the "medical home".

Indicators that measure the outcomes of care, especially those involving patients with multiple chronic conditions, have been especially challenging to develop. The creation of pay-for-performance programs has increased the importance of identifying appropriate indicators since a majority of health care encounters involve people with multiple chronic conditions. So far, the majority of the indicators used in the pay for performance programs have been process, not outcome, indicators. However, some evaluations suggest that some of these process measures do not always correlate with desired outcomes in pay for performance programs. ${ }^{3}$ Challenges in developing
Correspondence: Scott Berkowitz Johns Hopkins University School of Medicine, 600 North Wolfe Street, Carnegie 568, Baltimore, MD 21287 , USA

Fax +l 4106149422

Email sberkow3@jhmi.edu 
outcome measures include adequately correcting for the presence and severity of patient illness, co-morbidities as well as determining accountability among multiple clinicians caring for the patient.

In this report, we use Medicare data to examine three quality indicators that could be used to study regional variations in care. The first indicator is hospital admissions for ambulatory care-sensitive conditions (ACSC), defined as conditions which, when appropriately managed in the community, do not usually require a hospital admission. The second is 30-day inpatient readmissions, or a repeat hospitalization within one month of discharge. The third monitors the care for patients with three common chronic conditions: congestive heart failure (CHF), diabetes, and chronic obstructive pulmonary disease (COPD). Patients with chronic conditions such as these typically have multiple co-morbidities and providers and there is some evidence to suggest that the addition of specialty care can help promote better outcomes. $^{4-7}$

This paper uses these indicators to examine the regional variation in health outcomes across the 306 Dartmouth hospital referral regions (HRR). We also examine the level of correlation across the indicators to determine whether regions that score high on one indicator also score high on the other indicators. Based upon these findings we make specific recommendations on how the care for individuals with multiple chronic conditions and for people undergoing transitions could be improved.

\section{Methods}

We used data from the Medicare 5\% nationally random sample for 2004. The data base is a nationally representative random sample of all Medicare beneficiaries. Data were drawn from the Centers for Medicare \& Medicaid Services' Standard Analytic Files (SAF). The SAF enrollment file contains demographic information on each Medicare beneficiary and the beneficiary's associated claims files including expenditures, utilization, and diagnostic information at the individual beneficiary level for all Medicare covered services. To be included in the analysis, Medicare beneficiaries had to be aged 65 years or older, living in the United States and have both Medicare Part A and Part B fee-for-service coverage. Medicare beneficiaries enrolled in managed care, living outside of the US, or who did not have both Part A and B coverage were excluded because encounter data on these individuals were incomplete.

Hospitals were grouped into the 306 HRRs. These areas were developed by researchers at Dartmouth to represent regional health care markets for tertiary medical care. Each HRR contains at least one hospital that performed major cardiovascular procedures and neurosurgery. A HRR is defined by a collection of zip codes. ${ }^{8}$ Medicare Part A and B spending is adjusted for cost of living differences across the HRRs using metropolitan statistical area wage index values provided by CMS. ${ }^{9}$

The Agency of Healthcare Research and Quality (AHRQ) created quality indicators to identify ACSC under the auspices of its Quality Indicators project. ACSC conditions are defined in SAS software (SAS Institute, Cary, NC, USA) using the Prevention Quality Indicator specifications, but essentially are conditions, which when managed appropriately on an outpatient basis, typically do not require hospitalization. ${ }^{10}$ The definitions and uses of ACSC conditions have evolved considerably since first developed by Bindman and his colleagues at UCSF. ${ }^{11,12}$ Admissions for ACSC conditions have been used as a measure of access to, and quality of, care in the community. ${ }^{2}$ Using Medicare data we calculated three different ACSC measures: (1) rates of ACSC discharges for Medicare beneficiaries; (2) Medicare expenditures for ACSC discharges for Medicare beneficiaries; and (3) Medicare expenditures for ACSC discharges as a percent of total Medicare expenditures.

Hospital readmission rates are often used as an indicator of both inpatient quality of care and access to appropriate follow-up care in the community. ${ }^{2,13}$ We chose to present 30-day readmission rates although we also examined shorter and longer readmission rates. Thirty days was selected because it allows sufficient time for an adverse outcome associated with the initial indication for hospitalization to manifest, while concomitantly attempting to minimize the number of admissions due to other health issues. It is, however, recognized that some readmissions within 30 days will not be related to the initial hospitalization. We report two measures of readmissions: (1) hospital readmission rates within 30 days per 100 Medicare beneficiaries and (2) percent of total Medicare hospital expenditures associated with readmissions within 30 days.

We also examined the cost and outcomes of Medicare beneficiaries with three chronic diseases: $\mathrm{CHF}$, diabetes, and COPD. These three conditions were chosen because they are included in the Medicare chronic care demonstrations, they are common in the Medicare population, and because most Medicare beneficiaries with these conditions also have other co-morbidities. ${ }^{14}$ Specifically, we examined: (1) selected national quality forum indicators for each condition which constitute appropriate care, specifically those recommended 
in the Health Plan Employer Data and Information Set (HEDIS) standards from the National Committee for Quality Assurance (NCQA), and (2) total Medicare Part A and Part B reimbursements for beneficiaries with one or more of these conditions. ${ }^{15}$

Finally, we examined the correlation of the multiple indicators across the HRRs. The null hypothesis is that the score on one indicator will be uncorrelated with the scores on other indicators, ie, that there are no system-wide effects that result in a particular HRR having consistently good or consistently bad care across multiple indicators.

\section{Results}

In 2004, there were 1,577,380 Medicare beneficiaries in the national 5\% sample that met the enrollment qualifications. These beneficiaries had 537,136 hospital discharges and the mean Medicare (Parts A and B) per capita expenditure was $\$ 6085$.

In 2004, $12.6 \%$ of Medicare hospital spending involved ACSC conditions. Reducing the number of ACSC admissions would result in considerable savings to the Medicare program and improve health outcomes. There is significant regional variation across the 306 HRRs suggesting opportunity for improvement in certain HRRs. Table 1 presents the 10th, 50th, and 90th percentile values for the HRRs as well as the mean value. For example, the number of ACSC admissions per 1,000 Medicare beneficiaries in the 90th percentile is over twice the number in the 10 th percentile ( 85 vs 42 ). In addition, Medicare spending on ACSC admissions per beneficiary in the HRR was more than twice as high in the 90th percentile than in the 10th percentile, suggesting the savings potential in certain HRRs with better care coordination.

In 2004, 9.2\% of total Medicare hospital spending was attributable to readmissions within 30 days (Table 2). There were 2.4 readmissions per 100 Medicare beneficiaries. Reducing the number of readmissions would also result in

Table I Ambulatory care-sensitive conditions (ACSC) rates and expenditures

\begin{tabular}{lllll}
\hline & \multicolumn{4}{l}{ HRR percentile } \\
\cline { 2 - 5 } & Mean & $\mathbf{1 0 \%}$ & $\mathbf{5 0 \%}$ & $\mathbf{9 0 \%}$ \\
\hline $\begin{array}{l}\text { ACSC rate } \\
\text { (Per I,000 Medicare beneficiaries) }\end{array}$ & 65 & 42 & 63 & 85 \\
$\begin{array}{l}\text { ACSC expenditures } \\
\text { (Per Medicare beneficiary) }\end{array}$ & $\$ 39$ & $\$ 24$ & $\$ 38$ & $\$ 53$ \\
$\begin{array}{l}\text { Medicare hospital payments } \\
\text { attributable to ACSC }\end{array}$ & $12.6 \%$ & $9.9 \%$ & $12.5 \%$ & $15.4 \%$ \\
\hline
\end{tabular}

Abbreviation: HRR, Dartmouth hospital referral regions.
Table 2 Readmission rates and associated expenditures for Medicare beneficiaries

\begin{tabular}{lllll}
\hline & \multicolumn{4}{l}{ HRR percentile } \\
\cline { 2 - 5 } & Mean & $\mathbf{1 0 \%}$ & $\mathbf{5 0 \%}$ & $\mathbf{9 0 \%}$ \\
\hline $\begin{array}{l}\text { Readmission rate } \\
\text { (per 100 Medicare beneficiaries) }\end{array}$ & 2.4 & 1.5 & 2.4 & 3.4 \\
$\begin{array}{l}\text { Hospitalized Medicare beneficiaries } \\
\text { readmitted within 30 days }\end{array}$ & $18 \%$ & $14 \%$ & $18 \%$ & $22 \%$ \\
$\begin{array}{l}\text { Total Medicare hospital } \\
\text { expenditures associated with } \\
\text { readmissions within 30 days }\end{array}$ & $9.2 \%$ & $6.4 \%$ & $9.2 \%$ & $12.1 \%$ \\
\hline
\end{tabular}

Abbreviation: HRR, Dartmouth hospital referral regions.

considerable savings to the Medicare program, as well as improved health outcomes. Medicare beneficiaries located in the HRRs at the 90th percentile were more than twice as likely to be readmitted to a hospital as were beneficiaries located in the 10th percentile. On average, $18 \%$ of the Medicare beneficiaries who were discharged from an acute care hospital were readmitted within 30 days. The percent of hospitalized Medicare beneficiaries readmitted to the hospital following discharge varied across the HRR regions, from $14 \%$ in the 10 th percentile to $22 \%$ in the 90 th percentile. HRRs with high rates of readmissions also spent the largest portion of the Medicare hospital spending on readmissions within 30 days.

We also examined Medicare beneficiaries with three chronic conditions: CHF, COPD, and diabetes. Expenditures for Medicare beneficiaries with at least one of these chronic conditions accounted for $64.1 \%$ of Medicare spending in 2004. It must be noted that many of these Medicare beneficiaries had acute and chronic conditions in addition to these three chronic conditions and spending for all of their care is included in the $64.1 \%$ figure. In Table 3, we present the results for beneficiaries with all three chronic conditions in 2004. We also examined the results for beneficiaries with two of the diseases and for those who had only one of the chronic conditions. The distributions across the 306 HRRs were generally similar for those with only one or two of the diseases and are not presented here.

For patients with CHF, COPD, and diabetes, there were little differences across the 306 HRRs with respect to provider follow-up. Almost $90 \%$ of Medicare beneficiaries with all three chronic conditions received a follow-up visit within four weeks of hospital discharge and there was little variation between the 10th and 90th percentiles. In addition, almost $90 \%$ of Medicare beneficiaries with all three chronic conditions saw a clinician every six months and there was 
Table 3 Medicare beneficiary testing associated with congestive heart failure (CHF), Chronic obstructive pulmonary disease (COPD), and diabetes

\begin{tabular}{|c|c|c|c|c|}
\hline & \multicolumn{4}{|c|}{ HRR percentile } \\
\hline & Mean & $10 \%$ & $50 \%$ & $90 \%$ \\
\hline $\begin{array}{l}\text { Follow up physician visit } \\
\text { within four weeks of } \\
\text { hospitalization }\end{array}$ & $88.7 \%$ & $84.6 \%$ & $88.8 \%$ & $91.8 \%$ \\
\hline $\begin{array}{l}\text { Physician visit every } \\
\text { six months }\end{array}$ & $87.8 \%$ & $83.3 \%$ & $88.2 \%$ & $91.8 \%$ \\
\hline Cholesterol test & $36.4 \%$ & $18.0 \%$ & $35.7 \%$ & $54.1 \%$ \\
\hline Flu shot & $25.0 \%$ & $16.0 \%$ & $24.7 \%$ & $35.3 \%$ \\
\hline Eye exam & $39.6 \%$ & $29.2 \%$ & $39.4 \%$ & $50.0 \%$ \\
\hline $\mathrm{HbA}_{\mathrm{IC}}$ test & $45.3 \%$ & $30.7 \%$ & $44.8 \%$ & $57.8 \%$ \\
\hline Nephrology test & $36.4 \%$ & $24.4 \%$ & $36.3 \%$ & $47.5 \%$ \\
\hline $\begin{array}{l}\text { Mean Medicare part A and B } \\
\text { payment per beneficiary }\end{array}$ & $\$ 35,437$ & $\$ 24,669$ & $\$ 33,106$ & $\$ 50,315$ \\
\hline
\end{tabular}

Abbreviations: $\mathrm{HbA}_{\mathrm{IC}}$, glycosylated hemoglobin; HRR, Dartmouth hospital referral regions.

minimal geographic variation in this rate between the 10th and 90th percentiles.

Much greater geographic variation occurred in the percentage of Medicare beneficiaries receiving certain tests. For most of these tests, Medicare beneficiaries in the 90th percentile were nearly twice as likely to have received the appropriate care as beneficiaries in the 10th percentile. This suggests considerable opportunity for increasing the level of appropriate test ordering in some HRRs. Table 3 also illustrates the variation in annual Medicare Part A and B per capita spending for beneficiaries with all three chronic conditions. The expenses for Medicare beneficiaries in the 10th percentile were, on average, less than half those for beneficiaries in the 90th percentile.
We examined the correlation in the indicators across the HRRs to determine whether low performing HRRs on one indicator also performed poorly on other indicators. Table 4 shows relatively low correlation for most indicators, indicating that HRRs that score poorly on one indicator do not necessarily score poorly on another. Only a few indicators had simple correlations higher than 0.4 . The major exceptions were cholesterol screening, glycosylated hemoglobin $\left(\mathrm{HbA}_{1 c}\right)$ testing, and nephrology testing, which were all highly correlated. Because these three tests are often performed as a battery of tests, the correlation is not surprising. We accept the null hypothesis that performances across the indicators are uncorrelated and that there is not a consistent pattern across the HRRs in terms of overall performance.

\section{Discussion}

It is well established that there are significant regional differences in the quality of care provided in the United States. ACSC admission rates identify regions where there are admissions that probably could have been prevented through improved inpatient/outpatient coordination and management. Readmission rates within 30 days suggest a failed transition from the inpatient setting to the outpatient setting, hence resulting in a repeat admission with higher associated costs. Finally, the measures focused on adherence to appropriate testing and follow-up for beneficiaries with CHF, COPD, or diabetes suggest that patients with multiple chronic conditions are experiencing difficulties obtaining appropriate care in certain areas. In combination, these indicators suggest that regions need to improve their care for people undergoing transitions and for people with multiple chronic conditions.

Most of these indicators show significant levels of regional variation. Only in the areas of "follow-up within four weeks

Table 4 Correlation across quality indicators for Medicare beneficiaries

\begin{tabular}{|c|c|c|c|c|c|c|c|c|c|}
\hline & ACSC rate & $\begin{array}{l}\text { Readmit } \\
\text { rate }\end{array}$ & $\begin{array}{l}\text { Four-week } \\
\text { follow up }\end{array}$ & $\begin{array}{l}\text { Six-month } \\
\text { follow up }\end{array}$ & $\begin{array}{l}\text { Cholesterol } \\
\text { test }\end{array}$ & Flu shot & Eye exam & $\begin{array}{l}\mathrm{HbA}_{\mathrm{IC}} \\
\text { test }\end{array}$ & $\begin{array}{l}\text { Nephrology } \\
\text { test }\end{array}$ \\
\hline ACSC rate & 1.0 & & & & & & & & \\
\hline Readmit rate & 0.50 & 1.0 & & & & & & & \\
\hline Four-week follow up & -0.03 & 0.20 & 1.0 & & & & & & \\
\hline Six-month follow up & 0.06 & 0.16 & 0.51 & 1.0 & & & & & \\
\hline Cholesterol test & 0.04 & 0.17 & 0.27 & 0.2 & 1.0 & & & & \\
\hline Flu shot & -0.18 & -0.39 & 0.04 & 0.11 & -0.07 & 1.0 & & & \\
\hline Eye exam & -0.07 & -0.03 & 0.20 & 0.33 & 0.20 & -0.03 & 1.0 & & \\
\hline $\mathrm{HbA}_{\mathrm{IC}}$ test & 0.16 & 0.24 & 0.24 & 0.24 & 0.91 & -0.06 & 0.08 & 1.0 & \\
\hline Nephrology test & -0.003 & 0.123 & 0.30 & 0.38 & 0.86 & 0.01 & 0.24 & 0.81 & 1.0 \\
\hline
\end{tabular}

Abbreviations: ACSC, ambulatory care-sensitive conditions; $\mathrm{HbA}_{I C}$, glycosylated hemoglobin. 
of discharge" and "seeing a physician within six months" was there very little clinically significant difference from the best to the worse performers, as performance was universally good.

Surprisingly, there was little correlation across the high and low performing HRRs for most indicators. This suggests that performance on one indicator does not necessarily translate to performance on other indicators. The reasons for this lack of consistency probably varies at the regional level, but likely includes: insufficient clinical decision support, inadequate staffing levels, the absence of integrated and coordinated care teams, as well as population differences.

Decision support should improve as the application of health information technology (IT) expands in response to the federal stimulus bill. ${ }^{16}$ Proliferation of electronic medical record systems will improve access to patient information between and within institutions, prevent redundant testing, and flag a provider when a patient might be due for a particular evidence-based screening test. This would likely be most effective if the IT systems were coordinated at the regional level.

Developing coordinated and integrated care teams, and tailoring staffing adjustments to this objective, would be helpful in designing teams that focus on using evidence-based practices for managing individuals with multiple chronic illnesses, rather than focusing on isolated disease conditions. These systems would better enable hospital discharges to be more carefully coordinated with outpatient care teams. Closer outpatient management for blood pressure, diabetes, breathing status, fluid management, among other clinical measures, with the assistance of a multidisciplinary care team, would help to decrease unnecessary hospital admissions. In aggregate, these teams would likely help mitigate the discrepancy in performance in regions across a number of indicators.

Establishing care coordination models is complicated by the complex web of providers and services that those with multiple chronic conditions seek. One in every four Americans of all ages has multiple chronic conditions and these individuals typically see multiple providers during the year. ${ }^{17,18}$ Among the Medicare population, 23\% of the beneficiaries have five or more chronic conditions and they incur $68 \%$ of all Medicare expenditures. These beneficiaries also see an average of 13 physicians and fill 50 different prescriptions during the year. ${ }^{14}$ Coordinating care with multiple specialists can be quite difficult for a single provider, especially considering the constant medication and clinical status adjustments. Thus, more active care coordination programs, especially for high risk patients, would be very beneficial. One proposal is to establish a "medical home" for the Medicare beneficiary. The "medical home" is most likely to have the greatest impact on beneficiaries with multiple chronic conditions since their cost is often the highest and their quality of care often the lowest. This issue is more salient when considering that this population is also much more likely to experience hospital admissions and then repeat admissions secondary to chronic conditions. To provide the highest level of care across the continuum, these transitions from inpatient to outpatient care require systems that promote careful communication and collaboration among providers.

In addition to focusing on the care teams themselves, innovative care coordination models could focus on community-based approaches rather than hospital or local approaches. Adjusting the locus of responsibility and accountability would serve to create shared objectives and disincentivize isolated silos of care with less regard for integrated and patient-focused outcomes. Community approaches to reduce readmission rates and promote high quality care would likely be more effective than those practiced by hospitals or clinicians acting alone. This is especially true in a fee-for-service environment, where most of health care is delivered in the United States.

One possible approach is for all hospitals in the area to be involved in decreasing inappropriate readmissions by providing better care when patients are in the hospital as well as more effective integration into outpatient care. Increasingly, hospitalists care for inpatients, rather than the patient's usual outpatient physician. The benefit of this practice is increased focus and experience with inpatient medicine and better opportunity for active involvement in patient care issues during a typical day. The limitation is that this automatically increases transfers of care and creates opportunities for incomplete communication. This is further hampered by insufficient access to electronic medical records. Funding incentives are not often aligned for reducing readmissions; hospitalist funding rather is typically related to number of admissions per bed, which provides incentives for early discharges. All of these factors therefore increase the likelihood of poor transition back to the community health care setting.

Even with the implementation of structural changes necessary for sustaining a high quality system, motivating behavioral change among providers to maximize performance could still remain a challenge. The introduction of financial incentives could be a powerful tool employed to assist in this goal, in the form of a regional pay-for-performance program. As one example of how a regional program might be structured, communities with high readmission and/or ACSC rates or with poor rates of chronic condition compliance could be encouraged to generate community-level responses to the 
problem with pay for performance incentives. A regional pay for performance system could be implemented in many forms, most likely with phased-in objectives. Initially, the goal might be for all HRRs below the 50th percentile to reach the 50th percentile, and ultimately the original 10th percentile mark. All providers in the community exceeding the $50 \%$ benchmark would receive bonus payments in the following year while providers in poorly performing communities would not. The result would be a financial incentive for all providers to collaborate to create systems to improve care and reduce early re-admissions.

There are numerous obstacles to regional approaches, including difficulty in: 1) determining regional boundaries and a locus of responsibility, 2) achieving clinician and hospital buy-in, 3) aligning incentives to encourage participation, 4) providing financial assistance to overcome start-up costs, and 5) maintaining focus on the patient. Another problem is that any "unfunded mandate" might risk endangering the financial solvency of many providers.

A common denominator among potential solutions is that improved communication and collaboration among providers and institutions is needed. Care coordination might improve the facility of patient transfer from the inpatient to the outpatient communities, especially for high-risk patients with multiple chronic illnesses. Financial incentives may be needed to change the "silo" approach to medical care. Whichever approach is pursued, it must be clearly recognized that the variation in quality of care strongly suggests that much could be done to reduce costs while improving patient-centered care. Utilization of regional quality benchmarks, such as those described herein, would be one approach to establish and follow improvement. Patients with multiple chronic conditions are often cared for by several clinicians, and in the fee for service environment, innovative and effective approaches to coordinating this care must be sought.

\section{Disclosures}

The authors are grateful for the financial support of the Commonwealth Fund which helped fund the data analyses. The authors report no conflicts of interest in this work.

\section{References}

1. Wennberg JE, Fisher JS, Skinner ES. Geography and the debate over Medicare reform. Health Aff (Millwood). 2002;Suppl Web Exclusives: w96-w114.

2. Schoen C, Davis K, How SK, Schoenbaum SC. US health system performance: a national scorecard. Health Aff (Millwood). 2006;25(6): w457-w75.

3. Fonarow GC, Abraham WT, Albert NM, et al. Association between performance measures and clinical outcomes for patients hospitalized with heart failure. JAMA. 2007;297:61-70.

4. Ahmed A, Allman RM, Kiefe CI, et al. Association of consultation between generalists and cardiologists with quality and outcomes of heart failure care. Am Heart J. 2003;145:1086-1093.

5. Tseng FY, Lai MS. Effects of physician specialty on use of antidiabetes drugs, process and outcomes of diabetes care in a medical center. J Formos Med Assoc. 2006;105:821-831.

6. Ezekowitz JA, van Walraven C, McAlister FA, et al. Impact of specialist follow-up in outpatients with congestive heart failure. CMAJ. 2005;172:189-194.

7. Harrold LR, Field TS, Gurwitz JH. Knowledge, patterns of care, and outcomes of care for generalists and specialists. J Gen Intern Med. 1999;14:499-511.

8. The Dartmouth Atlas of Health Care. Data and methods FAQ. 2009. Available from: http://www.dartmouthatlas.org/faq/data.shtm. Accessed June 11, 2009.

9. Centers for Medicare \& Medicaid Services. Wage Index Files. Available from: http://www.cms.hhs.gov/AcuteInpatientPPS/WIFN/list. asp\#TopOfPage. Accessed June 11, 2009.

10. Agency for Healthcare Research and Quality. Prevention Quality Indicators. Available from: http://www.qualityindicators.ahrq.gov/ pqi_download.htm. Accessed June 11, 2009.

11. Bindman AB, Grumbach K, Osmond D, et al. Preventable hospitalizations and access to health care. JAMA. 1995;274:305-311.

12. Wolff JL, Starfield B, Anderson G. Prevalence, expenditures, and complications of multiple chronic conditions in the elderly. Arch Intern Med. 2002;162(20):2269-2276.

13. Anderson GF, Steinberg EP. Hospital readmissions in the Medicare population. N Engl J Med. 1984;311:1349-1353.

14. Anderson GF. Medicare and chronic conditions. N Engl J Med. 2005; 353:305-309.

15. National Committee for Quality Assurance. Available from: http://www. ncqa.org/. Accessed October 13, 2008.

16. Blumenthal DA. Stimulating the Adoption of Health IT. N Engl J Med. 2009;360:1477-1479.

17. Mollica RL, Gillespie J. Care coordination for people with multiple chronic conditions. Partnership for Solutions. Johns Hopkins University. January 2003. http://www.partnershipforsolutions.org/DMS/files/ Care_coordination.pdf. Accessed October 13, 2008.

18. Pham HH, Schrag D, O'Malley AS, Wu B, Bach PB. Care patterns in Medicare and their implications for pay for performance. N Engl J Med. 2007;356:1130-1139.
Risk Management and Healthcare Policy

\section{Publish your work in this journal}

Risk Management and Healthcare Policy is an international, peerreviewed, open access journal focusing on all aspects of public health, policy, and preventative measures to promote good health and improve morbidity and mortality in the population. The journal welcomes submitted papers covering original research, basic science, clinical \& epidemio-

\section{Dovepress}

logical studies, reviews and evaluations, guidelines, expert opinion and commentary, case reports and extended reports. The manuscript management system is completely online and includes a very quick and fair peerreview system, which is all easy to use. Visit http://www.dovepress.com/ testimonials.php to read real quotes from published authors. 